\title{
Abuelas de Plaza de Mayo, hijos de desaparecidos, nietos recuperados y hermanos*: de las "labores detectivescas" a las acciones y producciones culturales, artísticas y mediáticas
}

\author{
María Luisa Diz
}

Recibido: 6 de abril de 2018

Evaluado: 28 de julio de 2018

Aceptado: 23 de octubre de 2018

Citar como: Diz, M. L. (2019). Abuelas de Plaza de Mayo, hijos de desaparecidos, nietos recuperados y hermanos: de las "labores detectivescas" a las acciones y producciones culturales, artísticas y mediáticas. Hallazgos, 16(31), 61-89. Doi: https://doi.org/10.15332/ s1794-3841.2019.0031.03

\section{Resumen}

El presente artículo se propone construir una genealogía de prácticas dramáticas, performáticas y artísticas de Abuelas de Plaza de Mayo, de la generación de los hijos de desaparecidos, de nietos recuperados y de hermanos de nietos apropiados y recuperados, agrupados en Hijos e Hijas por la Identidad y la Justicia contra el Olvido y el Silencio (Hijos) y en Abuelas de Plaza de Mayo, que se realizaron en el escenario público entre fines de la década de los setenta y fines de la década de los noventa, que pueda ayudar a comprender, por un lado, por qué el teatro fue considerado por Abuelas de Plaza de Mayo el medio de comunicación artístico más indicado para reflexionar sobre la apropiación de menores como un delito que afecta la identidad social; y por otro, que pueda contribuir a entender por qué quienes se acercaron a colaborar con la causa político-institucional de Abuelas de Plaza de Mayo fueron actores y actrices, cuya profesión, tal como afirma el filósofo José Pablo Feinmann, consiste en encontrar sus identidades a través de los miles de rostros de lospersonajes que

Aquí cabe aclarar que, en este artículo, no se hará referencia a los hermanos de desaparecidos que se han nucleado en el organismo de derechos humanos Herman@s de Desaparecidos por la Verdad y la Justicia, sino a los hijos de desaparecidos que tienen hermanos apropiados o recuperados, y que se han agrupado en Abuelas de Plaza de Mayo.

** Este artículo de investigación forma parte de los resultados de la tesis doctoral Teatro x la ldentidad: un escenario para las luchas por la configuración de sentidos sobre la apropiación de menores y la restitución de la identidad, Facultad de Ciencias Sociales, Universidad de Buenos Aires, 2017, inédita.

*** Universidad de Buenos Aires, Argentina. Correo electrónico: mariludiz@hotmail.com ORCID: https://orcid.org/0000-0002-8107-3855 
encarnan. Se examinan el discurso institucional y las acciones de búsqueda, denuncia y difusión de Abuelas de Plaza de Mayo a partir de un enfoque que prioriza los aspectos culturales, artísticos y mediáticos de su trabajo institucional. Las prácticas de Abuelas de Plaza de Mayo son consideradas como tácticas o estrategias de acuerdo con los diferentes contextos histórico-políticos y los términos desarrollados por De Certeau. Para analizar las tácticas y estrategias, se toman los conceptos de teatralidades sociales, testimonio, familismo y narrativa humanitaria. Además, se tienen en cuenta los estudios sobre la renovación generacional en el movimiento de derechos humanos, a partir del surgimiento de Hijos en 1995, y las nociones de protestas performáticas motivadas por el trauma, ADN performático, performances y activismo artístico.

Palabras clave: Abuelas de Plaza de Mayo, hijos de desaparecidos, nietos recuperados, tácticas, estrategias, testimonio, performances. 


\section{Grandmothers of the Plaza de Mayo, children of the disappeared, recovered grandchildren and siblings: from "detective work" to cultural, artistic and media actions and productions}

Received: April 6, 2018

Evaluated: July 28, 2018 Accepted: October 23, 2018

\section{Abstract}

The present article proposes to build a genealogy of dramatic, performance and artistic practices of the Grandmothers of the Plaza de Mayo, the generation of the children of the disappeared, recovered grandchildren and siblings of appropriated and recovered grandchildren, grouped in Sons and Daughters for Identity and Justice against Oblivion and Silence (HIJOS, in Spanish) and Grandmothers of the Plaza de Mayo, that took place on the public stage between the end of the seventies and the end of the nineties, which can help to understand, on the one hand, why the theater was considered by the Grandmothers of the Plaza de Mayo as the most appropriate means of artistic communication to reflect on the appropriation of minors as a crime that affects social identity; and on the other hand, can contribute to understand why those who came to collaborate with the political-institutional cause of the Grandmothers of the Plaza de Mayo were actors and actresses, whose profession, as affirmed by the philosopher José Pablo Feinmann, is to find their identities through the thousands of faces of the characters they embody. The institutional discourse and the search, denounce and dissemination actions of the Grandmothers of the Plaza de Mayo are examined from an approach that prioritizes the cultural, artistic and media aspects of their institutional work. The practices of the Grandmothers of the Plaza de Mayo are considered as tactics or strategies according to the different historical-political contexts and the terms developed by De Certeau. To analyze the tactics and strategies, the concepts of social theatricalities, testimony, familism and humanitarian narrative are taken. In addition, studies 
on generational renewal in the human rights movement are taken into account, starting with the emergence of Hijos in 1995, and the notions of performative protests motivated by trauma, performative DNA, performances and artistic activism.

Keywords: Grandmothers of the Plaza de Mayo, children of the disappeared, recovered grandchildren, tactics, strategies, testimony, performances. 


\section{Avós da Praça de Maio, filhos de desaparecidos, netos recuperados e irmãos: dos "labores detetivescos" às ações e produções culturais, artísticas e mediáticas}

Recebido:6 de abril de 2018

Avaliado: 28 de julho de 2018 Aceito: 23 de outubro de 2018

\section{RESUMO}

Este artigo propõe construir uma genealogia de praticas dramáticas, performáticas e artísticas das Avós da Praça de Maio, da geração dos filhos dos desaparecidos, de netos recuperados e de irmãos de netos apropriados e recuperados, agrupados em Filhos e Filhas pela Identidade e a Justiça contra o Esquecimento e o Silêncio (Hijos) e em Avós da Praza de Maio, que se realizaram no cenário público entre o final da década dos anos sessenta e o final da década dos noventa, que possa ajudar a compreender, por um lado, por que o teatro foi considerado pelas Avós da Praça de Maio o meio de comunicação artístico mais indicado para refletir sobre a apropriação de menores como um delito que afeta à identidade social; e por outro, que possa contribuir a entender por que aqueles que se aproximaram a colaborar com a causa político-institucional das Avós da Praça de Maio foram atores e atrizes, cuja profissão, tal como afirma o filosofo José Pablo Feinmann consiste em encontrar suas identidades através dos milhares de rostos dos personagens que encarnam. Examina-se o discurso institucional e as ações de busca, denuncia e difusão das Avós da Praça de Maio a partir de um enfoque que prioriza os aspectos culturais, artísticos e mediáticos de seu trabalhão institucional. As praticas das Avós da Praça de Maio são consideradas como táctica ou estratégia de acordo com os diferentes contextos histórico-políticos e os termos desenvolvidos por De Certau. Para analisar as tácticas e estratégias, tomam-se os conceitos de teatralidades sociais, testemunha, familismo e narrativa humanitária. Além, se levam em consideração os estudos sobre a renovação geracional no movimento dos direitos 
humanos, a partir do surgimento de Hijos em 1995 e as noções de protestos performáticos motivados pelo trauma, ADN performático, performance e ativismo artístico.

Palavras-chave: Avós da Plaza de Maio, filhos de desaparecidos, netos recuperados, tácticas, estratégias, testemunha, performances. 


\section{El CARÁCTER TÁCTICO} Y DRAMÁTICO DE LAS PRIMERAS ACCIONES DE BÚSQUEDA, DE DENUNCIA Y DE VISIBILIZACIÓN PÚBLICA DE LA CAUSA DE Abuelas de Plaza de Mayo

En 1977,1 un subgrupo de madres de jóvenes detenidos/desaparecidos, pertenecientes a la Asociación Madres de Plaza de Mayo (constituida el 30 de abril de ese mismo año), comenzó a reunirse para buscar a sus nietos. Estos habían sido secuestrados en operativos militares junto con sus padres o habían nacido durante el cautiverio de sus madres embarazadas en centros clandestinos de detención durante la última dictadura cívico-militar argentina (1976-1983).

La apropiación de hijos de desaparecidos o de presos políticos fue un plan sistemático elaborado desde la alta cúpula militar. En 1984, el general Ramón Camps, perteneciente a esa cúpula, lo reconoció de esta manera: “Personalmente no eliminé ningún niño. Lo que hice fue llevar algunos de ellos

1 La constitución de Abuelas de Plaza de Mayo no tuvo un momento preciso ni un acto formal. Se considera como fecha oficial de su nacimiento el 21 de noviembre, día en que por primera vez se encontraron las doce fundadoras (El amante.com, 2000). El objetivo del encuentro era entregar un documento con los casos de niños "desaparecidos" y mujeres embarazadas a Cyrus Vance, secretario de Estado norteamericano, quien visitó la Argentina ese mes para concurrir a un acto en la Plaza San Martín con la finalidad de colocar un ramo de flores en la estatua del Libertador General San Martín. La visita de Vance cobraba un sentido particular para las madres y abuelas por cuanto la Administración del entonces presidente Jimmy Carter mostraba interés por esclarecer las violaciones a los derechos humanos cometidas por la dictadura argentina (Abuelas de Plaza de Mayo, 2007, p. 21). No obstante, Abuelas de Plaza de Mayo ha adoptado como fecha de su aniversario el 22 de octubre, día en que "se juntaron por primera vez para esbozar los lineamientos de su búsqueda e iniciar una lucha colectiva que sigue hasta hoy" (p. 19). Esta fecha fue instituida como el Día Nacional por el Derecho a la Identidad, mediante la sanción de la Ley 26.001 por el Congreso de la Nación en 2005 y coincide, además, con el cumpleaños de Estela de Carlotto, presidenta de Abuelas de Plaza de Mayo desde 1990. a organizaciones de caridad para que les encuentren nuevos padres. Los subversivos enseñan a sus hijos la subversión. Eso tenía que terminar" (Amnesty International, 1985, citado por Penchaszadeh, 2012, p. 266). La apropiación de menores fue una práctica única y distintiva del terrorismo de Estado en Argentina. Los hijos de padres concebidos por los militares como "subversivos" (Franco, 2012) eran apropiados por miembros de las Fuerzas Armadas o personas conectadas con el aparato represivo. Algunos eran ofrecidos en adopción a través del aparato judicial con información falsa acerca de su origen. De acuerdo con Calveiro (1999), los desaparecedores mataban a quien debian matar; preservaban la otra vida, le evitaban un hogar "subversivo" y se desentendían de su responsabilidad. De este modo, la apropiación fue funcional al proyecto político de la última dictadura que se propuso aniquilar a una clase considerada como "subversiva", el enemigo, lo absolutamente "otro", y promover la defensa de la civilización occidental y cristiana.

Mediante la ruptura del vínculo entre padres "subversivos" y sus hijos, y la crianza y educación de estos últimos en hogares con una cultura basada en los valores "occidentales y cristianos", los militares buscaban impedir la transmisión y herencia, no solo biológica, sino también cultural e identitaria. En suma, impedir la posibilidad de reproducción biológica y cultural- de los grupos "subversivos". En el acto de apropiación,

se conjugan dos lógicas clasificatorias sobre la pertenencia y la identidad. Por un lado, [...] que la cultura y la identidad en primera instancia se transfiere y hereda por la sangre [...]. Por otro lado, $[\ldots]$ que la educación $y$, por lo 
tanto, la cultura puede volver "puros" a los "impuros" [...]. En la lógica del apropiador parece existir la idea de que hay que arrancarlos de su sangre de origen para tornarlos personas $\mathrm{y}$ domesticarlos en su cultura. (Da Silva, 2001, pp. 130-131)

Sin embargo, más allá del carácter excepcional y único de la apropiación de menores, esta práctica se montó sobre un circuito jurídico-burocrático preexistente destinado a la "minoridad pobre" (Villalta, 2006). Este circuito

ha tenido desde las primeras décadas del siglo XX, cuando comienza a consolidarse como tal, una marcada impronta clasista y salvacionista, en la medida en que su objeto de intervención fue un sector de la infancia que, definido tradicionalmente por la carencia - ya que según la evaluación de distintos funcionarios, eran niños que por las condiciones de pobreza en que vivían no se encontraban protegidos adecuadamente, no poseían familias aptas para su crianza, en definitiva eran "menores abandonados" - permitía, al ser clasificado de esta forma, que otros lo tutelaran, institucionalizaran, adoptaran o apropiaran. (Villalta, 2006, p. 153)

Este circuito funcionó como condición de posibilidad para el desarrollo y la ejecución de un plan sistemático de apropiación de menores, en tanto los militares utilizaron y reelaboraron esa impronta salvacionista de la infancia carente y abandonada - sobre todo en términos morales - para definir un nuevo sector de la infancia por ser intervenido de manera violenta: el de los hijos de padres "subversivos".
Ahora bien, ante la sospecha de que algunos de esos bebés y niños hubieran sido ofrecidos mediante adopciones fraguadas por ese circuito jurídico-burocrático, el 15 de mayo de 1977, un grupo conformado por once abuelas firmó un habeas corpus colectivo en forma de carta, dirigida al Departamento Judicial de Morón, en la que hacían saber de la existencia de bebés "desaparecidos" y solicitaban que se suspendiesen todas las adopciones. ${ }^{2}$ Esa carta fue considerada, posteriormente, como un documento histórico y un antecedente inmediato de la constitución de Abuelas de Plaza de Mayo que surgió a partir de un proceso de confluencias entre mujeres en busca de sus nietos. ${ }^{3}$ En esta etapa primigenia, Abuelas de Plaza de Mayo se referían a los bebés y niños secuestrados junto con sus padres o aún en el vientre materno como "desaparecidos", en tanto todavía se desconocían los destinos que habían tenido aquellos.

El núcleo inicial de aquella búsqueda fueron doce madres/abuelas que tomaron inicialmente el nombre de Abuelas Argentinas con Nietitos Desaparecidos: Mirta Acuña de Baravalle, Beatriz H. C. Aicardi de

2 "Los bebés de nuestros hijos desaparecidos o muertos en estos últimos dos años. Algunas de estas criaturas han nacido de sus madres en cautiverio. Otra fue sacada de su hogar, que fue destruido. Hasta ahora todos nuestros esfuerzos han sido vanos. Las criaturas no han sido reintegradas a sus hogares, a sus familias. No sabemos ya qué hacer". Y sigue: "Últimamente ha llegado a nuestro conocimiento que algunos abuelos han podido localizar a sus nietos en Tribunales de menores o por su intermedio. Por eso nos permitimos rogarle quiera tener a bien interesarse en la lista de bebés desaparecidos que adjuntamos, por si ustedes tuvieran noticias de alguno de ellos" (Dandan, 2006)

3 En septiembre de 1977, Alicia Zubasnabar de la Cuadra, quien sería la primera presidenta de Abuelas de Plaza de Mayo, comenzó a asistir, junto con su esposo y Hebe de Bonafini, a las rondas de las madres en busca de un hijo, una hija embarazada, su nuera y su yerno. Al mismo tiempo, María Isabel Chorobik de Mariani había comenzado a buscar a otras madres que, como ella, tuvieran también nietos "desaparecidos" (Semanaprofesional.com, 2005). 
Neuhaus, María Eugenia Casinelli de García Irureta Goyena, Eva Márquez de Castillo Barrios, María Isabel Chorobik de Mariani, Celia Giovanola de Califano, Clara Jurado, Leontina Puebla de Pérez, Raquel Radío de Marizcurrena, Vilma Delinda Sesarego de Gutiérrez, Haydee Vallino de Lemos y Alicia Zubasnabar de De la Cuadra. Recién en 1979 adoptaron el nombre de Abuelas de Plaza de Mayo, tal como se las denominaba públicamente a nivel nacional e internacional. En los primeros meses, hubo arduas discusiones entre las madres sobre la conveniencia o no de que las abuelas se organizaran formalmente como grupo diferenciado de las madres. Si bien las madres insistían en que las abuelas tenían que formar un mismo grupo con ellas, ya que ambas tenían hijos desaparecidos, las abuelas pensaban que su búsqueda era distinta porque la situación de los bebés y niños secuestrados por las Fuerzas Armadas y de Seguridad era diferente de la de sus padres, y se precisaban estrategias y metodologías específicas para recuperarlos.

Durante los últimos años de la década de los setenta, en plena dictadura, las abuelas se iban conociendo, así como las madres, en las comisarías, los juzgados, las rondas de las madres, las colas del Ministerio del Interior y por el "boca a boca" se iban juntando. Se reunían en espacios públicos de la Ciudad de Buenos Aires: el Jardín Botánico, el Zoológico, algunas iglesias y confiterías como El Molino, Las Violetas, Café Tortoni, Richmond, London, entre otras; y en espacios privados: una habitación prestada dentro del departamento de las madres, casas de otras abuelas y un departamento alquilado. El objetivo de las reuniones era recopilar documentación sobre cada caso y realizar firmas conjuntas. Al mismo tiempo, otras abuelas se iban conociendo y reuniendo en algunas ciudades del interior del país, principalmente, en La Plata y Córdoba.

Las abuelas desarrollaron una serie de acciones de búsqueda de carácter institucional, tanto a nivel nacional como internacional: redactaron, al igual que las madres, habeas corpus que presentaban ante la justicia para averiguar el paradero de sus hijas embarazadas; visitaron juzgados de menores, casas cuna y orfelinatos; acudieron a embajadas; escribieron y enviaron cartas a funcionarios de todos los niveles, al entonces papa Pablo VI, la Corte Suprema de Justicia de la Nación, la Organización de las Naciones Unidas (ONU) y la Cruz Roja; concretaron entrevistas con militares, obispos y líderes políticos que pudieran aportar datos o apoyar la búsqueda. En la gran mayoría de los casos, estas instituciones y estos actores sociales a los que las abuelas recurrieron permanecieron inactivos, guardaron silencio, rechazaron las peticiones e inclusive, en algunos casos, las maltrataron.

Ante esta situación, según el discurso institucional, las abuelas comenzaron a emprender una serie de acciones propias de búsqueda de los bebés y niños. Una de ellas consistió en la visibilización pública de las fotografías de los rostros de esos bebés y niños en carpetas que incluían sus casos y que eran enviadas a personas dentro y fuera del país, llevando las fotos a los medios de comunicación y adhiriéndolas en las pancartas que portaban durante las rondas de las madres y otras movilizaciones de los organismos de derechos humanos. Al igual que las fotografías de los desaparecidos, las fotografías de los bebés y niños "desaparecidos" funcionaron como pruebas o evidencias de 
su existencia en estas primeras acciones de búsqueda, de denuncia y de visibilización pública de Abuelas de Plaza de Mayo.

Pero también las abuelas diseñaron y ejecutaron acciones que fueron concebidas por Abuelas de Plaza de Mayo como "labores detectivescas" (2007, p. 25). Estas labores las llevaron a crear una amplia red de recolección informal de datos. Esta red se fue construyendo a partir de tres ejes de investigación. En primer lugar, una búsqueda documental que implicaba recoger información de diversas fuentes, en particular, testimonios de enfermeras que habían presenciado partos en hospitales militares o centros clandestinos de detención, revisar certificados de nacimiento, reparando en aquellos firmados por médicos vinculados con la represión o en los que se señalaba que el parto había sido domiciliario, así como registros de adopciones que parecieran sospechosas, y tomar fotos de niños que podían llegar a ser sus nietos en jardines de infantes y escuelas. En segundo lugar, el diseño y la ejecución de acciones de camuflaje para intervenir en lugares públicos y privados sin ser descubiertas, tales como internarse en un sanatorio psiquiátrico para seguir una pista, disfrazarse de enfermera, trabajar como empleada doméstica en una casa para estar cerca de un menor, pasar por un domicilio simulando promocionar productos para bebés a fin de conseguir datos o llegar a ver a un menor. ${ }^{4}$ En tercer lugar, la recepción de datos y de denuncias de posibles casos de apropiación que eran aportados por parte de la ciudadanía, como vecinos de mujeres que habían aparecido con bebés sin haber estado embarazadas.

4 Los ejemplos mencionados fueron tomados del relato institucional de Abuelas de Plaza de Mayo (2007, p. 25).
A fines de la década de los setenta, las abuelas comenzaron a realizar viajes a países de América Latina y Europa, con el objetivo de contactarse con algunos sobrevivientes exiliados para recoger sus testimonios que confirmaron los nacimientos en cautiverio. Según el relato institucional, las abuelas "copiaron los datos en papel de seda y los ingresaron a la Argentina envueltos en una caja como si fueran bombones" (Abuelas de Plaza de Mayo, 2007, p. 33).

En este tipo de acciones de búsqueda, se puso en juego un cierto carácter dramáti$\mathrm{co}$, en tanto las abuelas escenificaron en el espacio público una serie de teatralidades sociales (Del Campo, 2004). ${ }^{5}$ Si bien la citada autora se refiere con este concepto a una articulación de estrategias dramáticas, las primeras acciones de búsqueda desarrolladas por las abuelas en este primer periodo podrían ser caracterizadas como tácticas (De Certeau, 1996). Se trataba de acciones calculadas que determinaban la ausencia de un lugar propio tanto en términos materiales como simbólicos. Aún no contaban con un espacio físico que funcionara como sede institucional, y sus figuras y su causa carecían de credibilidad y de legitimidad a nivel social. Por tanto, debían, parafraseando a De Certeau, utilizar hábilmente el tiempo, aprovechando las ocasiones que

5 Con el concepto de teatralidades sociales, esta autora se refiere a "la articulación, a partir de estrategias dramáticas (visuales, lingüísticas, sonoras, espaciales, sensoriales y en base a estilos, géneros y retóricas dramáticos) adoptadas por los aparatos e instituciones culturales y por los grupos subalternos para articular sus sentires respecto de la historia y el acontecer social y apelar - a partir de puestas en escena en la esfera pública cotidiana y en base a un imaginario compartido - a la sensibilidad social para modelarla con miras a constituir a esos espectadores en agentes activos de su propia historia o en receptores de las visiones de mundo articuladas por las autoridades culturales a partir de estos imaginarios" (Del Campo, 2004, pp. 49-50). 
este les presentaba, así como las grietas en los cimientos del poder para poder reunirse y buscar a sus nietos; y para visibilizar públicamente sus figuras y sus denuncias en medio de la censura y de las amenazas, de las listas negras, de los silencios voluntarios y en ocasiones obligados, y de los casos de periodistas exiliados, asesinados y desaparecidos. A modo de ejemplo, en 1978, las abuelas y las madres aprovecharon tácticamente la presencia de la prensa internacional que vino a cubrir el Campeonato Mundial de Fútbol que se realizó en nuestro país entre el 1 y el 25 de junio (utilizado por los militares para desprestigiar a quienes los denunciaban, para mostrar el entusiasmo de la población y para señalar que en la Argentina se respetaban los derechos humanos), con el objetivo de denunciar el accionar del terrorismo de Estado y de reclamar por el paradero de sus hijos.

Las abuelas, entonces, escenificaron públicamente una articulación de tácticas dramáticas. ${ }^{6}$ Estas tácticas eran visuales (trataban de parecer señoras mayores convencionales que tomaban el té $\mathrm{y}$, a veces, fingían celebrar el cumpleaños de alguna); lingüísticas (elaboraron un código para hablar por teléfono: "el hombre blanco" era el papa; "cachorros", "cuadernos" y "flores" eran los niños; las "chicas" o las "jóvenes" eran las madres, y las "viejas" o las "tías viejas" eran ellas mismas); sonoras (hablaban casi susurrando); espaciales (si era un edificio, se juntaban a la hora de la siesta para no cruzarse con el encargado, evitaban el uso del ascensor y bajaban las persianas); y sensoriales (muchas dejaron de fumar para que

6 La conceptualización de tácticas dramáticas fue elaborada a partir del mencionado concepto de teatralidades sociales de Del Campo. el olor a cigarrillo no las delatara). ${ }^{7}$ Estas tácticas se basaban en estilos, géneros y retóricas dramáticos que se asemejaban a los de la novela policial (Amaro, Cabrera y Caballero, 2005; Amorós, 1985; Hoveyda, 1967; Symons, 1982). El objetivo estaba puesto en resolver casos (de bebés y niños "desaparecidos"), utilizando la razón y basándose en la indagación y observación, o usando la intuición para investigar un hecho o una serie de acontecimientos que se produjeron con un claro quebranto de la ley.

A pesar de la censura mediática reinante, las madres comenzaron a concurrir a las redacciones de los diarios nacionales para denunciar públicamente las desapariciones de sus hijos, de sus nueras embarazadas y de sus nietos secuestrados junto con sus padres. Pero las madres y las abuelas debieron juntar firmas y dinero, ya que los dos diarios que, por lo general, aceptaban publicar este tipo de solicitadas, lo hacían a cambio del pago de una onerosa suma de dinero y de la presentación de los nombres de los responsables de las solicitadas y de sus certificados de domicilio. Uno de esos diarios fue el Buenos Aires Herald, distribuido en inglés, que se convirtió en el primer periódico que se atrevió a publicar en abril de 1978 una carta de lectores que daba cuenta de la existencia de niños "desaparecidos" en el país (Abuelas de Plaza de Mayo, 2007, p. 28).

A fines de la década de los setenta, los testimonios de los sobrevivientes exiliados, a los que se hizo referencia, les permitieron a las abuelas localizar y recuperar a los primeros

7 Los ejemplos mencionados entre paréntesis fueron tomados del relato institucional de Abuelas de Plaza de Mayo (2007, p. 23). 
nietos. ${ }^{8}$ Pero también les permitieron comprobar y demostrar la existencia de un plan sistemático de apropiación de bebés y niños (que incluía maternidades clandestinas, personal médico y listas de espera de personas involucradas en la represión, dispuestas a "adoptar" hijos de desaparecidos), con el objetivo de reclamar el juzgamiento y la condena de los responsables y cómplices de este delito. El 5 de agosto de 1978, para el Día del Niño, las abuelas lograron publicar en La Prensa - el otro diario que abrió sus páginas a los reclamos de los organismosuna carta dirigida a quienes se hubieran apropiado de sus nietos, titulada: "Llamado a la conciencia y a los corazones". 9 Según el relato institucional, esta solicitada no solo "puso a las Abuelas ante la mirada de la opinión pública", sino que también "estremeció al mundo y marcó el inicio del respaldo internacional a su causa" (Abuelas de Plaza de Mayo, 2007, p. 31).

8 "En agosto de 1979, con la ayuda de CLAMOR, las Abuelas localizaron en Chile a los hermanos Anatole Boris y Victoria Eva Julien Grisonas, secuestrados el 26 de septiembre de 1976 junto con sus padres, Victoria Lucía Grisonas y Mario Roger Julien -aún hoy desaparecidos-en el partido de San Martín, provincia de Buenos Aires. Anatole y Victoria hacía tres años que habían sido adoptados por un matrimonio que desconocía sus orígenes" (Abuelas de Plaza de Mayo, 2007, p. 33).

9 "Apelamos a las conciencias y a los corazones, de las personas que tengan a su cargo, hayan adoptado o tengan conocimiento de dónde se encuentran nuestros nietitos desaparecidos, para que en un gesto de profunda humanidad y caridad cristiana restituyan esos bebés al seno de las familias que viven la desesperación de ignorar su paradero. Ellos son los hijos de nuestros hijos desaparecidos 0 muertos en estos últimos dos años. Nosotras, Madres-Abuelas, hacemos hoy público nuestro diario clamor, recordando que la Ley de Dios ampara lo más inocente y puro de la Creación. También la ley de los hombres otorga a esas criaturas desvalidas el más elemental derecho: el de la vida, junto al amor de sus abuelas que las buscan día por día, sin descanso, y seguirán buscándolas mientras tengan un hálito de vida. Que el Señor ilumine a las personas que reciben las sonrisas y caricias de nuestros nietitos para que respondan a este angustioso llamado a sus conciencias" (Abuelas Argentinas con Nietitos Desaparecidos, citado por Nosiglia, 1985, p. 136).
A partir de la restauración democrática en 1983, las abuelas irrumpirán públicamente como asociación y sus acciones se tornarán más estratégicas para construir y disputar una visibilidad y legitimidad públicas en torno a sus figuras, su historia y su lucha.

\section{"Botín de guerra":}

\section{LA PRIMERA ESTRATEGIA}

INSTITUCIONAL DE DIFUSIÓN DE Abuelas de Plaza de Mayo Y DE SU CAUSA

El libro Botín de guerra, preparado por el periodista uruguayo Julio E. Nosiglia ${ }^{10}$ durante 1984, en coincidencia con la publicación del informe final de la Comisión Nacional sobre la Desaparición de Personas (Conadep), titulado Nunca más, y publicado en 1985, año en que se realizó el juicio a las tres juntas militares, constituye el primer texto institucional con el que Abuelas de Plaza de Mayo se propuso visibilizar públicamente la existencia de un plan sistemático de "desaparición" de bebés y niños ejecutado durante la última dictadura. En este libro,

la palabra apropiación no aparece con la carga semántica que tiene en la actualidad. Se habla de bebés y niños desaparecidos. [...] Releer Botín de guerra permite verificar cómo en 1985 aún era necesario experimentar palabras y descripciones para contar el horror de algo desconocido a nivel mundial:

10 No se conocen públicamente demasiados datos sobre la vida y obra de Nosiglia. Solo se sabe que escribió, además, dos libros previos a Botín de guerra, El partido intransigente y El desarrollismo en 1983, como parte de la Colección Biblioteca Política Argentina, publicados en Buenos Aires por el Centro Editor de América Latina. En 2000 denunció por plagio a David Blaustein, realizador del documental homónimo Botín de guerra, por reproducir fragmentos de su libro sin su autorización. 
la represión y el robo de bebés y niños por parte de los agentes de un Estado represor. (Da Silva, 2005, p. 127)

El libro efectúa una recopilación, secuenciación y sistematización de una serie de relatos testimoniales que funcionan a modo de evidencias para denunciar con nombres, apellidos y cargos a algunos miembros de las Fuerzas Armadas y de Seguridad como responsables de la ejecución de aquel plan. Pero también para denunciar a otros actores sociales que son mencionados debido a su complicidad por acción u omisión, como jueces de menores, la mayor parte de la jerarquía de la Iglesia católica y otras religiones, miembros de partidos políticos, médicos y parteras, dueños de medios de comunicación, etc. En el prólogo de la reedición del libro en 2007 (en el trigésimo aniversario de Abuelas de Plaza de Mayo), se revela otro de los propósitos fundamentales de aquella primera gran estrategia de difusión: generar conciencia social en torno al delito de sustracción de menores como condición de posibilidad para ampliar la mencionada red de recolección informal de datos, mediante el aporte de noticias sobre los hijos y nietos buscados por parte de la ciudadanía (Estela de Carlotto, citado por Nosiglia, 2007, p. 11).

Nosiglia compiló e intervino una serie de relatos testimoniales de Abuelas de Plaza de Mayo y de otros familiares de menores "desaparecidos", entre ellos, algunos sobrevivientes exiliados que sufrieron la sustracción de sus hijos. La importancia del testimonio en la memoria social reside en que el testimonio constituye "una de las puestas-en-relato que mayor capacidad de interpelación tiene", ya que "pone en escena una corporización biográfica que desvía el 'idioma común' de referencia colectiva de la historia hacia lo singular-personal" (Richard, 2002, p. 192). Además, la relevancia del testimonio para comprender la violencia política radica en que ese relato no es solo transmisión, sino también interpretación de la experiencia; contiene diferentes destinaciones, interlocuciones y fuentes; y la distancia temporal suma experiencias e interpretaciones propias de otras temporalidades (Oberti, 2009, p. 130). En este sentido, Botín de guerra interpela a los lectores desde el tratamiento literario o narrativo de los testimonios de familiares de menores "desaparecidos" que transmiten e interpretan las experiencias singulares-personales de “desaparición" y de restitución. Además, la elección del autor de seleccionar únicamente testimonios de familiares es coherente, en esos primeros años del periodo posdictatorial, con el fenómeno que Jelin denominó familismo, en tanto "la 'verdad' [en torno al pasado reciente] fue identificándose con la posición de "afectado/a directo/a", primero en la voz de los parientes directos de las víctimas de la represión estatal" (2006/2010, p. 167). De este modo, los familiares de desaparecidos agrupados en organismos de derechos humanos "evocaron sus lazos biológicos con los ausentes para hacer sus reclamos de justicia" (Sosa, 2012, p. 43).

El libro está dividido en dos grandes partes que organizan cronológicamente los acontecimientos: "Los secuestros" y "Los reencuentros". Ambas partes están formadas por ocho y seis capítulos, respectivamente. Los capítulos comienzan con las palabras del autor en itálica (para diferenciarse de las voces de los testimonios que aparecen entrecomilladas), que cumplen la función de presentar y de contextualizar cada caso; 
y de entretejer las historias personales y colectivas, a través de una forma de escritura que se asemeja a la del relato novelesco, cuyo propósito es describir acontecimientos, lugares, personas, caracteres, sentimientos, etc.

En "Los secuestros", los relatos testimoniales reconstruyen un antes y un después en las historias de las familias que sufrieron, en muchos casos, los secuestros de varios de sus miembros en manos de operativos militares y policiales, entre ellos, de mujeres embarazadas, bebés y niños. Los secuestros aparecen como acontecimientos que implicaron la ruptura violenta de la cotidianidad de sus vidas, así como se describe su modus operandi. Estos relatos de los familiares suelen ser interrumpidos para dar lugar a la reproducción de comunicados oficiales que fueron publicados por la prensa gráfica en los que se denomina a los hombres y las mujeres secuestrados "subversivos", "comunistas", "guerrilleros" e "ideólogos", cuyas muertes se produjeron como resultado de "enfrentamientos" con las Fuerzas Armadas. También se replican declaraciones posteriores ante la justicia de los represores que formaron parte de los operativos para ser interrogadas y puestas en cuestión por el autor. A continuación, los relatos de los familiares son retomados para disputar esos sentidos que habían sido impuestos por la última dictadura en torno a la identidad de los secuestrados. Estos, en cambio, son denominados por sus familiares "estudiantes", "trabajadores", "patriotas", "los que trabajaban en villas", "aquellos que luchaban por una sociedad más justa", "los mártires de una sociedad injusta", "una generación que quiso cambiar la sociedad", "una generación de resistentes", "una generación sacrificada", "quienes ofrendaron sus vidas" y "que no se sabe por qué se los llevaron".

En particular, las embarazadas detenidas-desaparecidas son presentadas por los relatos de sus familiares a partir de sus nombres, ocupaciones, fechas de nacimiento, de cuántos meses se encontraban embarazadas en el momento de su desaparición, día, hora aproximada y lugar o domicilio donde fueron secuestradas. En este sentido, el libro busca caracterizar a los desaparecidos que aparecen consignados en él, no solo como hijos jóvenes, sino también como padres y madres a quienes les sustrajeron a sus hijos. Este libro opta por representar a estos desaparecidos a partir de una reproducción del uso de la narrativa humanitaria ${ }^{11}$ (Laqueur, 1996; Markarian, 2004; Sikkink, 1996) efectuado por los testimonios de los familiares de desaparecidos como estrategia de denuncia y como estrategia de representación de los desaparecidos en el escenario público en la década de los ochenta. En este sentido, en Botín de guerra, los relatos de los familiares hacen énfasis en los padecimientos corporales que los desaparecidos sufrieron durante las torturas; en la mención de sus datos identitarios básicos (nombre, sexo, edad, ocupación) y de sus valores morales, en sus pertenencias familiares y en la omisión de sus compromisos político-ideológicos, con el fin de evitar la acusación de "subversivos" que, por entonces,

11 La narrativa humanitaria "concebía al cuerpo humano como un vínculo entre quienes sufren y quienes están en posición de ayudar a detener ese sufrimiento, y se basaba en la descripción minuciosa como prueba de veracidad [...]. Los profusos detalles de los 'cuerpos sufrientes de los otros' buscaban despertar compasión [...] que era presentada como un 'imperativo moral' para actuar en el sentido de mejorar esa situación" (Markarian, 2004, p. 103; Laqueur, 1996, pp. 177-178) 
aún era reproducida por los medios de comunicación y gran parte de la sociedad. En los primeros años de la posdictadura, esta narrativa no estaba instalada socialmente $y$ los modos de representación en torno a los desaparecidos aún estaban en debate por la vigencia de la "teoría de los dos demonios", que equiparaba los actos de violencia y de terrorismo perpetrados por las Fuerzas Armadas durante la última dictadura con los de las organizaciones guerrilleras durante la última dictadura y los años previos al golpe (1973-1976). “La temprana construcción de los desaparecidos como inocentes debió estructurarse en paralelo a aquel discurso binario sobre la responsabilidad de la violencia, en tanto y en cuanto, si no se los diferenciaba de aquellos 'culpables' del infierno, no podían ser construidos como víctimas" (Franco, 2012, citados por Feld y Franco, 2015, p. 41).

Por su parte, las palabras del autor revelan los diversos destinos que tuvieron algunos de los menores que fueron sustraídos de sus padres biológicos (institutos de menores, vecinos de la familia biológica, adopciones ilegales, miembros del sistema represivo y familias allegadas a ellos, muertos y enterrados como NN o la falsificación de sus muertes); enumeran la gravedad de las consecuencias psicofísicas y sociales ocasionadas por la desaparición de los menores (desintegración familiar, marginación social, falta de apoyo, dificultad de entender el propio estado civil, ruptura violenta de vínculos afectivos, carencia lógica de una estructura de personalidad, shock traumático, interrupción del desarrollo evolutivo, ruptura de identidad, sensación de confusión sobre el origen, desinformación acerca de la propia historia y aniquilación de las condiciones de equilibrio y afecto); y sostienen que deben ser restituidos a sus familias legítimas, entendiendo por restitución "que esos niños sepan y conozcan su historia" (Nosiglia, 1985/2007, p. 61). De esta manera, el libro pretende disputar los sentidos que infundían el temor de que la restitución provocara daños en las criaturas, y que planteaban que la "desaparición" de niños era algo irreversible y su perpetuación un mal menor, ya que se trataba de chicos que habían sido abandonados. Estos sentidos también habían sido impuestos por la última dictadura, y reproducidos por los medios de comunicación y gran parte de la sociedad.

Por su parte, el autor va hilvanando las historias particulares de cada abuela para dar cuenta de cómo se fueron conociendo y reuniendo en la búsqueda solitaria de los hijos y nietos; y cómo comenzaron a crear una metodología de búsqueda conjunta, de carácter táctico y dramático (tal como fue analizada en el apartado anterior), pero también de carácter institucional. $\mathrm{El}$ autor construye una metáfora biológica de la figura de las abuelas como "hormiguitas" y "abejas" en tanto, podría decirse, unas como otras se caracterizan por su naturaleza femenina, el trabajo colectivo y organizado, su capacidad para defenderse, aprovechar recursos y sortear obstáculos. En consonancia con esta metáfora, el autor pretende visibilizar ese trabajo de "hormiguitas" y "abejas" de las abuelas reproduciendo documentos redactados por ellas y dirigidos a los tribunales de justicia, cartas enviadas a representantes de la Iglesia, solicitudes elevadas a los militares en el poder, pronunciamientos contra el régimen, cartas para sus nietos, muestras del respaldo internacional obtenido, así como de las 
amenazas recibidas. Estos documentos funcionan a modo de pruebas o evidencias que buscan contribuir a la configuración y transmisión de un relato en sentido heroico que hace énfasis en las virtudes de las abuelas y en las hazañas de su lucha histórica como asociación.

De este modo, podría decirse que Botín de guerra constituye una estrategia (De Certeau, 1996), en tanto construyó un lugar propio de Abuelas de Plaza de Mayo - material y simbólico- sobre el tiempo, como colectivo u organización. Desde este lugar textual e institucional, las abuelas administraron relaciones de alianza y de oposición con diversos actores sociales para construir y disputar una visibilidad y legitimidad públicas en torno a su causa por la búsqueda de los nietos y a la denuncia por sus "desapariciones".

En "Los reencuentros", los relatos testimoniales dan cuenta de los intrincados itinerarios recorridos por parte de algunos de los menores, y también de las abuelas y de otros familiares para recabar datos, con el objetivo de dar con sus paraderos. Estos datos, en muchos casos, provenían de informantes y de denunciantes anónimos. Los relatos de las abuelas y de los familiares hacen énfasis en las características, sobre todo físicas, de los nietos buscados, y en los padecimientos físicos y psíquicos que sufrieron muchos de ellos: maltratos, desamor, abandono, soledad, etc. El relato de estos padecimientos otorga sentido al nombre del libro que concibe a estos menores como "botín de guerra", con el objetivo de denunciar públicamente el despojo de la condición humana al que habían sido sometidos:
Ser asesinados durante acciones represivas, ser masacrados en el vientre de sus madres, ser torturados antes o después del nacimiento, ver la luz en condiciones infrahumanas, ser testigos del avasallamiento sufrido por sus seres más queridos, ser regalados como si fueran animales, ser vendidos como objeto de consumo, ser adoptados enfermizamente por los mismos que habían destruido a sus progenitores, ser arrojados a la soledad de los asilos y de los hospitales, ser convertidos en esclavos desprovistos de identidad y libertad. (Nosiglia, 1985, p. 8)

De este modo, los relatos de los familiares, con ayuda de la prosa del autor, también configuran una narrativa en clave humanitaria centrada en la ruptura de los vínculos de sangre entre los menores y sus familias biológicas, y en los detalles de los padecimientos de los menores, con el objetivo de impedir su señalamiento mediático y social como hijos de "subversivos", de manera similar a la mencionada disputa en torno a la representación de las identidades de sus padres y madres desaparecidos.

Por su parte, los relatos reconstruyen las diversas experiencias de restitución logradas y certificadas, por lo que se denomina en el libro "la ley de la sangre" (Nosiglia, 1987, p. 197). Esta frase hace referencia a la identidad genética, a la que le otorga el carácter de una regla o norma constante e invariable que permite demostrar la filiación biológica. Para conocer la identidad genética de una persona, se realiza un análisis de material genético (ácido desoxirribonucleico $[\mathrm{ADN}])$. Este análisis consiste en tomar una muestra de ese material que contiene 
"células de un individuo, vivo o muerto, ya sea obtenida directamente (sangre, saliva, bulbo piloso, restos óseos, etc.), ya sea a partir de células recogidas del ambiente (manchas de sangre, saliva, células descamadas en ropa interior y otros objetos, etc.)" (Pechaszadeh, 2012, pp. 263-264). Ese ADN necesita ser cotejado con el de personas que puedan ser parientes biológicos del proveedor de la muestra. En el caso de los menores apropiados, cuyos padres se encuentran desaparecidos, el ADN de aquellos debe ser cotejado con el de sus abuelos. Este cotejo se efectúa mediante un marcador de consanguinidad, conocido como "índice de abuelidad", ${ }^{12}$ confirmado por parte de las abuelas en 1984, año en que se estaba preparando Botín de guerra. ${ }^{13}$ El descubrimiento de este índice generó un efecto de sentido sobre el concepto de identidad de Abuelas de Plaza de Mayo: "A partir de la posibilidad de demostrar genéticamente la filiación $-y$ por ende el delito de apropiación - , la recurrencia al aspecto biológico de la identidad se ha hecho cada vez más dominante" (Quintana, 2011, p. 47).

12 "La probabilidad o índice de 'abuelidad' es la probabilidad de que un set particular de abuelos sean efectivamente los abuelos biológicos de un niño en particular. Dado que los genes se heredan de padres a hijos, es obvio que todos los genes presentes en un individuo provienen de sus cuatro abuelos" (Penchaszadeh, 2012, p. 269).

13 En 1982, María Isabel Chorobik de Mariani y Estela de Carlotto, por entonces presidenta y vicepresidenta de Abuelas de Plaza de Mayo, respectivamente, visitaron en Nueva York a Víctor B. Penchaszadeh, médico genetista que se encontraba exiliado en esa ciudad. Este les explicó que se podrían aplicar los mismos análisis utilizados en las pruebas de paternidad y adaptar los cálculos probabilísticos que se utilizan en esas pruebas para calcular la probabilidad de "abuelidad”. La acción colectiva de varios genetistas y matemáticos, encabezados por la estadounidense Mary-Claire King y el chileno exiliado en los Estados Unidos Cristian Orrego, apoyados por el ítalo-norteamericano Luca Cavalli-Sforza y el francés Pierre Darlu, desarrollaron, en menos de un año, la metodología para el cálculo de la probabilidad de abuelidad (Penchaszadeh, 2012, p. 268).
Finalmente, el epílogo, escrito y firmado por el autor, toma la palabra como voz autorizada para legitimar la continuidad y vigencia de la lucha de las abuelas, para demandar la restitución de los menores, el juzgamiento y la condena de los responsables y cómplices, y para interpelar a los lectores mediante una "invitación $-\mathrm{y}$ hasta casi un ruego que ninguno podemos desechar-" (Nosiglia, 1985, p. 348). De esta manera, el autor construye un nosotros, en el que se incluye, para llamar imperativamente a los lectores a cerrar el libro y a comprometerse con la búsqueda de las abuelas.

El autor evoca un afiche elaborado por Abuelas de Plaza de Mayo en el que aparece la imagen en blanco y negro de un niño vestido de manera informal con una campera, un short y un par de zapatillas que está de pie sobre una vereda formada por baldosas cuadradas. El niño está ubicado hacia la derecha del afiche, de perfil y con la cabeza inclinada hacia abajo generando una sensación de tristeza. En una de sus manos, sostiene un aerosol de color negro con el que ha escrito un mensaje sobre una pared que, en realidad, es un papel desplegado que ha sido previamente doblado en pequeños cuadrados que hacen juego con las baldosas de la vereda. El mensaje está escrito en letra cursiva, aquella que la escuela les enseña a los niños para que aprendan a escribir: "Mi abuela me está buscando. Ayúdela a encontrarme" (Nosiglia, 1987, p. 353). El niño queda pequeño en proporción al tamaño del mensaje escrito por él, connotando la necesidad de que este mensaje escrito sobre la pared/el papel sea visible públicamente, pero también transmitido de boca a boca. El juego de colores entre blancos y negros produce la articulación de los 
binomios de pureza de la infancia/impureza de la infancia de los niños apropiados y de luz/oscuridad sobre una búsqueda invertida: la de los nietos que buscan a sus abuelas. Esta imagen puede ser vista como una suerte de vaticinio por parte de la asociación de la búsqueda que será emprendida por algunos nietos apropiados cuando alcancen la adolescencia o la adultez.

\section{El SURGIMIENTO EN EL ESCENARIO PÚBLICO DE LOS HIJOS, NIETOS Y HERMANOS: SUS ESTRATEGIAS DE BÚSQUEDA Y DE DIFUSIÓN}

Desde mediados de la década de los noventa comenzó a activarse un proceso de "eclosión o boom de la memoria" (Lvovich y Bisquert, 2008), a partir de la confluencia de una serie de factores. Entre ellos, se destacan las declaraciones públicas de algunos represores, ${ }^{14}$ y el juzgamiento y la condena a prisión de algunos militares implicados en el delito de apropiación de menores y de sustitución de identidades, gracias al accionar legal por parte de un grupo de Abuelas de Plaza de Mayo. ${ }^{15}$ Este proceso memorial

14 Se hace referencia a las declaraciones de Adolfo Scilingo sobre su participación en los "vuelos de la muerte", realizadas en el programa de televisión Hora clave conducido por Mariano Grondona, y que dieron lugar, posteriormente, a las de Julio Simón, Héctor Vergez y Víctor Ibáñez. Estas declaraciones fueron construidas mediáticamente como el "arrepentimiento" de los exrepresores. Mientras que las declaraciones del entonces jefe del Ejército, teniente general Martín Balza, en el programa periodístico de Bernardo Neustadt Tiempo nuevo, fueron interpretadas como una "autocrítica" a la actuación de las Fuerzas Armadas durante la última dictadura (Feld, 2001).

15 "En 1997 un grupo de cinco abuelas (María Isabel de Mariani, Cecilia Fernández de Viñas, Elsa Pavón de Grinspon, Rosa de Roisinblit e Isabella Valenzi) iniciaron por intermedio de sus abogados una causa por sustracción de sus nietos que contemplaba tres situaciones diferentes: niños desaparecidos de sus hogares, niños nacidos durante el cautiverio con sus madres en centros clandestinos, y niños desaparecidos durante el cautiverio de sus padres y posteriormente dio lugar al surgimiento de nuevas iniciativas y emprendimientos de carácter público por parte de diversos actores de la sociedad civil en acciones relacionadas con la configuración y transmisión de la memoria del pasado reciente, ${ }^{16}$ así como a la visibilización pública de nuevos actores sociales, cuyas voces fueron ganando autoridad y legitimidad en la escena pública. Este es el caso del surgimiento, en 1995, de Hijos e Hijas por la Identidad y la Justicia contra el Olvido y el Silencio (Hijos), en que participaban algunos nietos recuperados. "La incorporación de las nuevas generaciones provocó cambios y un rejuvenecimiento en las prácticas y los discursos del movimiento de DD. HH. [...] La aparición pública de los hijos de desaparecidos fue parte de ese proceso" (Bonaldi, 2006, pp. 157-158).

Ante la vigencia de las leyes de Punto Final (1986) y de Obediencia Debida (1987), y los indultos otorgados por el entonces presidente Carlos Menem, entre 1989 y 1990 (que impedían el pleno y efectivo juzgamiento de los militares y civiles implicados en violaciones a los derechos humanos cometidas

hallados asesinados. Esta causa se presentó ante el juez Bagnasco quien después de dos años dictó procesamiento y prisión a Eduardo Massera, Reynaldo Bignone, Cristino Nicolaides, Rubén Franco, Jorge "Tigre" Acosta, Antonio Vañek y Héctor Febre por los delitos de sustracción de menores y supresión de identidad relacionados a embarazadas que dieron a luz en la Escuela Mecánica de la Armada entre los años 1976 y 1979. Menos Acosta y Febres, el resto de los militares pasó a cumplir prisión domiciliaria por tener, al igual que Videla, más de setenta años" (Da Silva, 2001, pp. 251-252).

16 La presentación de proyectos para la construcción de museos y monumentos, y la recuperación de marcas territoriales; la realización de actos de homenaje a las víctimas y conmemoraciones públicas en fechas significativas; la conformación de bancos de datos, archivos y centros documentales con testimonios gráficos y visuales; la elaboración de artículos periodísticos y académicos; la organización de manifestaciones y producciones artísticas y literarias; la discusión por la transmisión de una narrativa sobre el pasado a las nuevas generaciones en la currícula escolar; y el impulso del tratamiento de temas referidos al pasado en los medios de comunicación. 
durante la última dictadura, Hijos desarrolló una nueva forma de protesta y reclamo simbólico de justicia en el espacio público: el escrache. Como afirma la consigna de Hijos: "Si no hay justicia, hay escrache". La génesis de los escraches se remonta a la sumatoria de una serie de ensayos de formas de actos y eventos denominados hasta ese momento repudio hacia algunos represores (Da Silva, 2001). La metodología de los escraches requería un trabajo previo para obtener datos precisos del represor por ser escrachado (biografía, dirección) y un contacto con los vecinos para mostrarles una foto e indicarles el domicilio del represor, con el objetivo de sensibilizarlos y pedirles que participaran del escrache. La estructura del escrache consistía en la reunión de los participantes en un punto (hijos y familiares de desaparecidos, sus amigos, sobrevivientes de centros clandestinos de detención y militantes de derechos humanos) para dirigirse hacia el lugar donde se procedía a identificar el domicilio del represor, y publicitar a los vecinos su presencia y los delitos cometidos por él durante la última dictadura mediante la lectura de un documento y las pintadas con aerosol en la calle, la vereda y las paredes (Da Silva, 2001, pp. 267-271).

Con el tiempo, los escraches comenzaron a incorporar colectivos de artistas que incluyeron "otros dispositivos, como pequeñas performances, objetos y pinturas" (Ursi y Verzero, 2011, p. 9). Entre estos colectivos, se destacan las acciones y producciones del Grupo de Arte Callejero (GAC) ${ }^{17}$ y del Gru-

17 "Se forma en 1997 por iniciativa de un grupo de estudiantes de la Escuela Nacional de Bellas Artes Prilidiano Pueyrredón que, sintiendo que el circuito tradicional no los representa, deciden intervenir el espacio público callejero (Grupo de Arte Callejero [GAC], 1997). po Etcétera ${ }^{18}$ que utilizaron recursos del juego y de las artes escénicas para intervenir en el espacio público con un fin contestatario o de denuncia, invitando a los vecinos a ser partícipes. Una de las acciones más conocidas del GAC fue utilizar y resignificar los sentidos de las señales viales que eran pegados en los postes de la calle para marcar las distancias a las que se encontraban los vecinos de un barrio de los lugares donde funcionaron centros clandestinos de detención y de los domicilios de represores no juzgados. Por su parte, el Grupo Etcétera propuso utilizar globos rellenos de pintura que, al arrojarse sobre los policías, impactaban y manchaban los muros. Ante las represiones, utilizaron formatos de encuestas para transmitir informaciones en los barrios y distribuyeron sobres en los que aparecía el teléfono y la frase "Llame ya" con algunos datos sobre la historia del represor en cuestión, un mapa para ubicar la casa y una bombita de látex para ser rellenada con pintura (Grupo Etcétera, citado por Diéguez, 2007, p. 132).

Pero los escraches no solo incluían performances en las que se solía satirizar a los represores, sino que, además, ellos mismos constituían performances o, mejor dicho, protestas performáticas motivadas por el trauma (Taylor, 2006). Estas “visibilizan no solo las repercusiones individuales, colectivas, intergeneracionales y hasta nacionales de

18 "Hacia fines de 1997 algunos artistas, en su mayoría de 20 años 0 menos, iniciándose en la poesía, el teatro, las artes visuales y la música, comenzamos a experimentar colectivamente el deseo de conformar un grupo y ser parte de un movimiento con el cual podríamos interactuar en diferentes escenarios sociales, llevando el arte a las calles, a los espacios de conflicto social, como así mismo desplazar estos conflictos sociales hacia otros espacios en los cuales permanecían silenciados (instituciones culturales, medios de comunicación masiva, los mega eventos instalados por la industria cultural)" (Grupo Etcétera, 1998). 
las violaciones a los derechos humanos en el largo plazo, sino también su modo de afectar comunidades enteras y de movilizar demandas por la justicia social" (p. 1675). Dentro de esta concepción, la citada autora también incluye las rondas de las madres y Teatro $x$ la Identidad, considerado como uno de los "brazos artísticos" de abuelas. Si bien se trata de intervenciones diferentes, las conecta mediante la noción de $A D N$ performático que, "no solo transmite material genético, sino también líneas de protesta y experiencias performáticas" (Taylor, 2002, p. 154), que son resignificadas por las sucesivas generaciones. De acuerdo con esta autora, los escraches son teatrales porque "la acusación funciona solamente si la gente la nota: títeres gigantes, cerdos militares con alas y en ocasiones pancartas enormes con fotografías de los desaparecidos acompañan a los manifestantes conforme estos cantan por las calles" (p. 151). En este sentido, los escraches poseen un "espíritu festivo, entre circense y carnavalesco" (Bonaldi, 2006, p. 167), ya que, además, incluyen murgas, personas disfrazadas, lanzallamas y malabaristas. De esta manera, los escraches aportaron a la causa por la memoria, la verdad y la justicia del movimiento de derechos humanos una forma festiva para poner en evidencia y denunciar públicamente a los represores que se diferenciaba del tono solemne, doloroso y triste que caracterizaba a las movilizaciones de aquel movimiento.

Ahora bien, a partir de mediados de la década de los noventa, Abuelas de Plaza de Mayo comenzó a atravesar un proceso de renovación generacional. Esta renovación se produjo por la incorporación de hijos de desaparecidos, nietos recuperados y hermanos de nietos apropiados y recuperados al trabajo institucional de la asociación. “El ingreso de un grupo de jóvenes provocó una modificación sustancial, si no en los objetivos de la institución, sí en el mensaje y en la forma de transmitirlo" (Bonaldi, 2006, p. 158). Según el relato institucional,

en aquel momento, el grupo de jóvenes que generaba actividades artísticas estaba compuesto por María José Lavalle y su hermana restituida, Paula Sansone, Mariana Eva Pérez - hermana de un joven apropiado-, Pedro Riva - amigo de las nietas-, Demián Córdoba -integrante del equipo de genética-, Victoria Grigera - hija de desaparecidos-, y las nietas recuperadas Laura Scaccheri y Elena Gallinari. (Abuelas de Plaza de Mayo, 2007, p. 111)

Este grupo de jóvenes formado por hijos de desaparecidos, nietos recuperados, hermanos de nietos apropiados y recuperados, allegados a estos e integrantes de los equipos de Abuelas de Plaza de Mayo le aportaron a la asociación producciones artísticas y actividades en las que brindaban sus testimonios para visibilizar públicamente sus figuras y su causa.

La primera estrategia de visibilización pública de este grupo de jóvenes consistió en la reposición, en 1997, de un montaje-instalación titulado El laberinto en la Segunda Bienal de Arte Joven, organizada por la Federación Universitaria de Buenos Aires (FUBA) en Parque Chacabuco. Ese montaje-instalación había sido realizado y expuesto por este grupo en el Centro Cultural General San Martín de la Ciudad de Buenos Aires, el 24 de marzo de 1996, fecha en que se conmemoraba el vigésimo aniversario 
del golpe militar de $1976 .{ }^{19}$ La pintora Patricia Aballay, una de las artistas plásticas que ayudó al grupo, cuenta al respecto:

La instalación se abría con un telón negro, en números chiquitos decía 1976, y allí comenzaba el recorrido. Un allanamiento representado con juguetes, los vuelos, el colegio, el Mundial '78, el gatillo fácil. Todas escenas nacidas de los recuerdos de los chicos. Adriana Vallejos, Oscar Chiecher y yo los fuimos escuchando y tratando de colaborar en todo lo que podíamos. (Abuelas de Plaza de Mayo, 2007, p. 110)

Este montaje-instalación podría ser concebido como una forma de activismo artístico (Longoni, 2009), ${ }^{20}$ ya que utilizó recursos teatrales (telón negro, escenas) para construir una ecuación que establece y repudia una continuidad histórica, y sin salida, entre el pasado (la apropiación de los hijos de desaparecidos por parte de las Fuerzas Armadas y de Seguridad) y el presente (los casos de abusos policiales hacia jóvenes pertenecientes a clases socioeconómicas bajas).

No obstante, la reposición de El laberinto en la Segunda Bienal parece haberle otorgado una mayor visibilidad pública a esta forma de activismo artístico, no tanto por su contenido en sí, sino más bien por el contexto y las circunstancias de su reposición. Los organizadores habían asignado a los

19 Varios autores (Crenzel, 2008; Feld, 2002; Lvovich y Bisquert, 2008; Rabotnikof, 2007; Valdéz, 2001; Vezzetti, 2002) coinciden en marcar el vigésimo aniversario del golpe militar conmemorado en 1996 como el punto de inflexión para este nuevo momento de "eclosión 0 boom de la memoria".

20 Esta definición busca agrupar a "producciones y acciones, muchas veces colectivas, que abrevan en recursos artísticos con la voluntad de tomar posición e incidir de alguna forma en el territorio de lo político" (Longoni, 2009, p. 18). organismos de derechos humanos un sitio ubicado debajo de la autopista 25 de Mayo, que atraviesa el parque. Un lugar, si se quiere, invisible y hasta marginal que también parecían ocupar, por entonces, las causas del movimiento de derechos humanos a nivel social. Allí, entonces, el grupo de jóvenes - al que se incorporó la nieta recuperada Tatiana Sfiligoy, el estudiante de Letras César Núñez y Yamila Grandi, hermana de un joven apropiado- montó la instalación. Al día siguiente de comenzar la muestra, el grupo llegó y se encontró con pintadas de esvásticas por todas partes. Con respecto a este hecho, Tatiana cuenta: "Fue muy triste. Se suponía que en la Bienal, donde había gente joven, no podían suceder esas cosas" (Abuelas de Plaza de Mayo, 2007, p. 113). Pero esa manifestación simbólica parecía significar que la instalación había resultado visible, a pesar del lugar geográfico otorgado, y a su vez había logrado visibilizar la existencia de una disputa memorial con sectores juveniles adherentes a la ideología del nazismo alemán, que había formado parte, en varios aspectos, del marco ideológico de la última dictadura cívico-militar argentina. $^{21}$

Por otro lado, algunos integrantes de este grupo de jóvenes, en particular nietos

21 En la década de los setenta, la influencia del nacionalismo integrista de la década de los treinta y la admiración del nazismo alemán posibilitaron la asimilación a la Doctrina de la Seguridad Nacional de la percepción de la vida como guerra. En este marco, para la percepción militar, el enemigo pasó de estar localizado en las ya inexistentes organizaciones armadas a la sociedad civil. Además, las corrientes tradicionales de antisemitismo social, la influencia ideológica del nazismo sobre el amplio espectro de las Fuerzas Armadas y en los grupos paramilitares de ultraderecha, que desde 1975 operaban bajo tutela militar contra las guerrillas, y un nacionalismo integralista y católico que era parte de la doctrina mencionada, explica el ensañamiento particular de la represión con sus víctimas judías, así como el hecho de que el judío, por el solo hecho de serlo, fuera automáticamente sospechoso de ser parte del enemigo (CO.SO.FAM., 1999). 
recuperados y hermanos de nietos apropiados y recuperados, comenzaron a brindar sus testimonios sobre sus historias y sobre la búsqueda de sus pares apropiados en la Facultad de Arquitectura, Diseño y Urbanismo de la Universidad de Buenos Aires (UBA), gracias a un contacto establecido por Madres de Plaza de Mayo Línea Fundadora; y a invitar a profesionales vinculados al diseño gráfico para la elaboración de materiales de difusión para el vigésimo aniversario de Abuelas de Plaza de Mayo, por cumplirse en 1997.22 Aquellas actividades en las que estos jóvenes brindaban sus testimonios podrían ser concebidas como performances testimoniales, en los dos sentidos o usos propuestos por Taylor de la performance: ${ }^{23}$ como estrategias que se pusieron

22 En la marcha número mil de Madres de Plaza de Mayo Línea Fundadora, Marcelo Castillo, uno de los curadores de la Bienal de Arte Joven, había asistido como colaborador junto con el centro de estudiantes de la Facultad de Arquitectura, Diseño y Urbanismo de la UBA. Al pasar por el estand de Abuelas de Plaza de Mayo, Mabe "Tati" Almeida, una madre de la línea fundadora, le presentó a las nietas María José y Tatiana. Castillo las invitó a la Facultad de Arquitectura a dar una charla sobre los veinte años del golpe, en la cátedra de Diseño Gráfico de Ricardo Méndez, que ya estaba trabajando sobre el tema. María José invitó a Castillo a una reunión en la casa de las abuelas. Este se ofreció a colaborar con la producción de una memoria gráfica, que resume la historia y los logros de la asociación, y comprometió a los profesores titulares Ricardo Méndez, Raúl Bellucia y Oscar Valdés para trabajar con sus alumnos en la producción de afiches sobre los veinte años de Abuelas de Plaza de Mayo, a partir de los relatos de las experiencias de búsqueda de una abuela, un nieto y un hermano. Los trabajos recorrieron e interior del país y fueron expuestos en el acto central del vigésimo aniversario, en el Centro Cultural San Martín. En 1999, se realizó una versión en inglés de la Memoria Gráfica y Castillo, junto con el fotógrafo Damián Sondereguer, la digitalizaron con el objetivo de que pudiera ser actualizada periódicamente. Además, Castillo propuso al Consejo Directivo la creación de un "rincón de las abuelas" en e Pabellón III de la Ciudad Universitaria donde se instaló la Memoria Gráfica y los trabajos realizados por los alumnos (Abuelas de Plaza de Mayo, 2007, pp. 112-113, 117-119, 128)

23 Taylor concibe las performances como estrategias que se ponen en acto en un escenario y bajo un guion determinados (1997) y que "funcionan como actos vitales de transferencia, transmitiendo saber social, memoria y sentido de identidad a través de acciones reiteradas" (2011, p. 20) en acto en el escenario educativo universitario bajo un guion preparado de antemano por nietos y hermanos con el objetivo de transmitir saberes, memorias y sentidos sobre el delito de apropiación de menores y sobre la restitución de la identidad a sus pares generacionales, con la idea de que entre ellos podían llegar a encontrarse nietos apropiados.

Por su parte, dentro de la agrupación Hijos se creó, en 1998 y a nivel nacional, la Comisión Hermanos. Esta comisión se orientó a colaborar en la búsqueda de los hermanos biológicos de los hijos de desaparecidos que militaban en la agrupación, así como de los generacionalmente considerados hermanos por ser hijos de la generación de los padres y compañeros desaparecidos. Por otro lado, hay un grupo de hermanos de nietos apropiados, que también son nietos de las abuelas, que supera numéricamente al grupo de nietos recuperados y que ha adquirido una gran visibilidad pública en los últimos años, en tanto actor social que fue ganando lugar y generando iniciativas dentro de Abuelas de Plaza de Mayo. A nivel institucional, según el estatuto formal de la asociación, los hermanos van reemplazando formalmente a las abuelas. Algunos de ellos, inclusive, participan en el trabajo de la institución y en las reuniones de la Comisión Directiva.

En los espacios público y mediático, este grupo de hermanos ha sido promotor de diversas estrategias de búsqueda y de difusión, produciendo sus propios discursos sobre las temáticas de la apropiación de menores y de la restitución de la identidad. Entre estas estrategias, se destacan el blog Tus hermanas te buscan (Battistiol, 2016), la 
iniciativa de Historietas x la Identidad, así como charlas y testimonios visuales.

El blog fue realizado por Flavia y Lorena Battistiol con el objetivo de localizar y de difundir la búsqueda de un hermano o hermana que se encontraba aún en el vientre materno en el momento del secuestro de sus padres. Este blog es una suerte de álbum familiar virtual que, presentado en un orden cronológico inverso (en el que lo más reciente que se ha publicado es lo primero que aparece en pantalla), contiene fotos y datos identitarios básicos de los padres desaparecidos y de Flavia y Lorena, y un listado de indicios para que, quien los lea, pueda llegar a sospechar que es el hermano que buscan. También se encuentran testimonios visuales de nietos recuperados, de Flavia y Lorena, y de su historia de búsqueda abordada por una de las Historietas x la Identidad.

Estas historietas fueron realizadas con la colaboración de diversos dibujantes, ilustradores y guionistas. En su mayoría, refieren a una historia de búsqueda y están relatadas desde la voz del hermano que busca. De manera similar al blog, las historietas representan, pero en un orden cronológico, una historia de búsqueda a través de fotos y de datos identitarios básicos de los padres desaparecidos, de los hermanos y de otros miembros de la familia, e indicios como rasgos físicos, y lugar y fecha aproximada de nacimiento del hermano buscado. Estas historietas también fueron publicadas en un blog. La elección de esta herramienta digital como estrategia de búsqueda y de difusión, por parte de los hermanos de nietos apropiados, reside en que el blog funciona a modo de bitácora o diario personal, pero también a modo de bitácora o diario familiar. Esta estrategia contribuye a visibilizar públicamente estas historias de búsqueda, con la posibilidad de ser actualizadas con frecuencia y, a menudo, comentadas por los lectores.

\section{UNA NUEVA METODOLOGÍA DE BÚSQUEDA}

En el vigésimo aniversario del golpe del 24 de marzo de 1976, en 1996, se organizaron y realizaron actividades conmemorativas durante todo el mes de marzo. "Los eventos conmemorativos del vigésimo aniversario del golpe son un momento de instalación societal de los temas sostenidos hasta ese momento por los organismos de derechos humanos". Entre los factores que influyeron en esta instalación, se destacan la difusión y cobertura por parte de los medios gráficos de los eventos, "haciéndose portavoces de un discurso que antes era patrimonio exclusivo de los organismos", y los "cambios en las formas de conmemoración que abrieron la participación a sectores que antes se podían sentir excluidos de los actos" (Lorenz, 2002 , p. 89). Esto se puede observar en los dos actos centrales "en repudio al golpe" que se realizaron en Plaza de Mayo: por un lado, un recital de rock organizado por Madres de Plaza de Mayo, la noche del 23 en vísperas del 24, que reunió a veinte mil personas, la mayoría jóvenes. Este acto fue el escenario de la primera aparición pública de Hijos. Por el otro, la marcha y concentración del 24 convocada por la Comisión por la Memoria, la Verdad y la Justicia. Los organizadores calcularon unos cien mil asistentes, entre los que se encontraban organizaciones vinculadas a la defensa de los derechos civiles y minorías (gais y lesbianas, víctimas de la violencia policial, 
desocupados, etc.), grupos familiares y manifestantes independientes. El acto finalizó con un recital y la presencia de murgas (Lorenz, 2002).

A pesar de esta instalación social de temáticas vinculadas a los organismos de derechos humanos, las abuelas tenían grandes dificultades para llegar con su causa a los medios. La apropiación de menores aún era poco tratada $\mathrm{y}$, muchas veces, los abordajes iban a contramano de lo que las abuelas pretendían visibilizar públicamente. Tal fue el caso de los mellizos Reggiardo Tolosa quienes, por entonces, promediaban los veinte años y "fueron expuestos en programas de televisión conducidos por simpatizantes de la dictadura, en los que se invitaba al matrimonio apropiador o se lo conectaba vía telefónica, cuando el juez había prohibido claramente el contacto con los chicos y más aún su exposición en los medios" (Abuelas de Plaza de Mayo, 2007, p. 103). Esos programas fueron Tiempo nuevo, conducido por Bernardo Neustadt, y HEL, de Daniel Hadad y Marcelo Longobardi. Neustadt les decía a los mellizos: "Acá afuera está su mamá histórica" y se preguntaba cómo podía ser que "un juez joven" - en referencia al juez Ballestero quien, a fines de 1993, había ordenado restituir los mellizos a su familia biológica - "tuviera que esperar a que los medios le dijeran para decidirse a cambiar la guarda de los chicos" (p. 103). Por su parte, la producción del programa de Hadad y Longobardi “invitó a las Abuelas con el acuerdo de que los mellizos no estarían en el piso. Pero violando dicho acuerdo y las recomendaciones del juez los periodistas hicieron ingresar a los chicos. Las Abuelas se retiraron del estudio y nunca se explicó a la audiencia lo que había ocurrido" (p. 103).
En uno de esos programas, uno de los mellizos dijo: "Mamita, si me separan de vos, me muero, me mato; solamente la muerte puede separarnos". En esta escena, en la que uno de los mellizos reclama que no los separen de sus apropiadores, se produjo una escena fantasma, esto es, "una escena doble, la otra escena, una escena que permanece muda, que es un doble siniestro de la escena que se muestra y que se ve por televisión". Esta escena es la "escena terrorífica de aquello que, no pudiendo haber sido hablado, simbolizado, se repite y retorna como alucinatorio" (García, 1994, pp. 20-21): el reclamo para que no los separaran de su madre biológica desaparecida.

Según Abel Madariaga, secretario de Abuelas de Plaza de Mayo, a partir de este tipo de situaciones, la asociación decidió tener una "nueva política institucional en relación a los medios que hizo que Abuelas comenzaran a generar material de archivo propio para ofrecer a todos aquellos que quisieran saber sobre la apropiación de niños y sobre su búsqueda" (Abuelas de Plaza de Mayo, 2007, p. 112). Esta decisión podría ser interpretada como un punto de quiebre entre un antes y un después en las estrategias institucionales de búsqueda y de difusión de Abuelas de Plaza de Mayo. A partir de este momento, estas estrategias no solo comenzarán a otorgarles importancia a los medios, sino que también tomarán una iniciativa con respecto a ellos.

Pero, además, crear una nueva política institucional de medios también implicaba constituir un público destinatario y producir estrategias de difusión para llegar a esa audiencia. Madariaga recuerda que, el 24 de marzo de 1996, cuan do pasó por el acto 
de Madres de Plaza de Mayo en plaza Congreso, vio que se encontraban allí algunos actores y actrices jóvenes ${ }^{24}$ que en ese momento protagonizaban la tira Montaña rusa ${ }^{25}$ en Canal 13: "Estos actores tenían la misma edad de los nietos apropiados, probablemente miraban los mismos programas, escuchaban la misma música y concurrían a los mismos sitios. La identificación de los jóvenes buscados con otros jóvenes de su misma generación podía convertirse en una herramienta más" (Abuelas de Plaza de Mayo, 2007, p. 111).

Esta anécdota sirve para ilustrar de qué manera Abuelas de Plaza de Mayo comenzaba a delinear una política institucional de difusión que tendría como público destinatario a aquellos jóvenes nacidos durante el periodo dictatorial, entre los que podían encontrarse los nietos que buscaban. La mencionada renovación generacional que se produjo en el movimiento de derechos humanos provocó un cambio en la imagen que las abuelas en tanto tales y en cuanto institución - tenían de sus nietos como bebés y niños hacia la construcción de una nueva imagen como jóvenes. Por tanto, en ese momento, la asociación se había planteado que debía configurar y transmitir sus mensajes teniendo en cuenta la edad que promediaban los nietos que buscaban a finales de la década de los noventa. Los documentos oficiales de

24 Esta tira dio a conocer a actores y actrices que luego se consagrarían en la pequeña pantalla, como Gastón Pauls, Nancy Dupláa, Esteban Prol, Carla Peterson, Diego Olivera, Diego Ramos, etc.

25 Según la sinopsis de la tira, Mariana (Nancy Dupláa) es una chica de 16 años que vive con su madre Liliana (Beatriz Spelzini) y su hermano menor, Facundo (Juan Gabriel Yacuzi). Ambos hermanos conviven con la pareja de su madre, Guillermo (Horacio Peña). Guillermo está divorciado y tiene un hijo de 20 años llamado Alejandro (Gastón Pauls). Todo cambiará en la vida de Mariana cuando ambos se conozcan y se enamoren mutuamente.
Abuelas de Plaza de Mayo cuentan que, a partir de la constatación de ese cambio etario, surgió la idea de que ya no tenían que dirigirse a quienes podían llegar a tener a sus nietos. Podían hablarles a ellos mismos porque ya tenían autonomía de decisión y podían hacerlo a través de otros jóvenes hijos de desaparecidos, nietos recuperados, hermanos de nietos apropiados y recuperados, y personalidades de la cultura, el arte y los medios de esa generación - con quienes, quizá, sus nietos compartían discursos, sentidos y prácticas que, por entonces, aparecían como las nuevas vías para localizar a más nietos y profundizar la instalación social de su causa. De esta manera, las nuevas estrategias de búsqueda y de difusión de Abuelas de Plaza de Mayo corrieron los límites del familismo, incluyendo a otros actores sociales no asociados a la lucha por los derechos humanos para que hablaran públicamente sobre el delito de apropiación de menores. ${ }^{26}$

\section{Conclusiones}

Las denominadas tácticas dramáticas les permitieron a las abuelas construir personajes, situaciones, códigos y acciones para camuflarse y aprovechar las ocasiones que se le presentaban en plena dictadura para intervenir y reunirse en lugares públicos y privados sin ser descubiertas, a fin de averiguar y compartir informaciones provenientes de diversas fuentes sobre los hijos y nietos buscados. El libro Botín de guerra, en cambio,

26 Aquí cabe destacar que el familismo implica "un alto grado de exclusión de otras voces sociales - por ejemplo, ancladas en la ciudadanía o en una perspectiva más universal referida a la condición humana - en la discusión pública de los sentidos del pasado y de las políticas a seguir en relación con ese pasado" (Jelin, 2006/2010, pp. 167-168). 
posibilitó la irrupción pública de las abuelas como asociación o colectivo de lucha a través del tratamiento literario o narrativo de los testimonios de familiares de desaparecidos y de menores, por entonces, considerados también como "desaparecidos" para denunciar la existencia de un plan sistemático de “desaparición" de bebés y niños e interpelar a los lectores a aportar datos sobre los hijos y nietos buscados. Los escraches de Hijos le brindaron al movimiento de derechos humanos en general, y a abuelas en particular, algunos de sus elementos y el espíritu festivo que se diferenció del tono solemne, triste y doloroso de las prácticas y de los discursos de aquel movimiento. En particular, la renovación generacional en Abuelas de Plaza de Mayo, con la participación institucional de hijos de desaparecidos, nietos recuperados y hermanos de nietos apropiados y recuperados otorgó a la asociación estrategias de búsqueda y de difusión propias, tales como activismos artísticos y performances testimoniales, herramientas digitales como los blogs, y relatos ficcionales como las historietas para visibilizar públicamente las figuras e historias de hijos, nietos y hermanos. Estas acciones y producciones funcionaron como condiciones de posibilidad para que, a partir de su vigésimo aniversario en 1997, Abuelas de Plaza de Mayo elaboraran nuevas estrategias de búsqueda y de difusión culturales, artísticas y mediáticas, entre ellas, spots y producciones audiovisuales. Los spots para televisión de Abuelas de Plaza de Mayo tomaron de las estrategias de búsqueda y de difusión de hijos, nietos y hermanos la articulación entre los géneros ficcional y testimonial e incluyeron mensajes institucionales para instalar el principio movilizador de la duda en el público de la generación de los nietos apropiados - primero jóvenes y luego adultos, padres y madres - en torno a la construcción de tres ejes temáticos: el nombre, la sangre y el testimonio. Los tres unitarios de Televisión por la identidad retomaron y reelaboraron la articulación entre ficción, testimonios reales y mensaje institucional para potenciar la llegada de la apropiación de menores y el trabajo institucional de Abuelas de Plaza de Mayo a una audiencia masiva. Sus materiales educativos, en particular los programas de televisión destinados al público infanto-juvenil, también retomaron aquella articulación entre ficción y testimonio, pero exenta de representaciones del horror, para hablarle al nuevo público de la generación de los bisnietos, con el objetivo, no solo de la búsqueda de los nietos ahora padres, sino también de la transmisión a las nuevas generaciones de un relato institucional sobre la apropiación de menores y el trabajo de Abuelas de Plaza de Mayo.

\section{REFERENCIAS}

Abuelas de Plaza de Mayo. (2007). La historia de Abuelas: 30 años de búsqueda, 19772007. Buenos Aires, Argentina: Autor.

Amaro Castro, L., Cabrera Pommiez, M. y Caballero Gatica, A. (2005). Lengua castellana y comunicación 2. Santiago de Chile, Chile: Santillana.

Amorós, A. (1985). Introducción a la novela contemporánea. Madrid, España: Cátedra.

Battistiol, F. y L. (2016). Tus hermanas te buscan [Mensaje en un blog]. Recuperado de http://tushermanastebuscan. blogspot.com.ar/

Bonaldi, P. D. (2006). Hijos de desaparecidos: entre la construcción de la política y la construcción de la memoria. En E. Jelin y D. Sempol (Comps.), El pasado en el 
futuro: los movimientos juveniles (pp. 143184). Buenos Aires, Argentina: Siglo XXI.

Calveiro, P. (1999). Poder y desaparición: los campos de concentración en Argentina. Buenos Aires, Argentina: Colihue.

CO.SO.FAM. (1999). La violación de los derechos humanos de argentinos judios bajo el régimen militar (1976-1983). Recuperado de http://www.desaparecidos.org/ nuncamas/web/investig/cosofam/cosofam0.htm

Crenzel, E. (2008). La historia política del Nunca más: la memoria de las desapariciones en la Argentina. Buenos Aires, Argentina: Siglo XXI.

Da Silva Catela, L. (2001). No habrá flores en la tumba del pasado: la experiencia de reconstrucción del mundo de los familiares de desaparecidos. La Plata, Argentina: Al Margen.

Da Silva Catela, L. (2005). Un juego de espejos. Violencia, nombres, identidades: un análisis antropológico sobre las apropiaciones de niños durante la última dictadura militar argentina. Telar, 2(2-3), 125-140.

Dandan, A. (2006, abril 9). El otro archivo de la memoria. Página/12. Recuperado de https://www.pagina12.com.ar/diario/elpais/1-65380-2006-04-09.htm

De Certeau, M. (1996). La invención de lo cotidiano 1: Artes de hacer. Ciudad de México, México: Universidad Iberoamericana.

Del Campo, A. (2004). Teatralidad, identidad nacional y memoria histórica como categorías espectaculares modeladoras de sensibilidades sociales. En Autor, Teatralidades de la memoria: rituales de reconciliación en el Chile de la transición (pp. 38-84). Santiago de Chile, Chile: Mosquito comunicaciones.
Diéguez Caballero, I. (2007). Escenarios liminares: teatralidades, perfomance y política. Buenos Aires, Argentina: Atuel.

El amante.com. (2000, noviembre 4). La historia que cuenta "Botín de guerra". Recuperado de http://web.archive.org/ web/20080605005152/http:/www.elamante.com:80/nota/0/0284.shtml

Feld, C. (2001). La construcción del “arrepentimiento": los ex represores en la televisión. Entrepasados, 10(20), 35-53.

Feld, C. (2002). Del estrado a la pantalla: las imágenes del juicio a los ex comandantes en Argentina. Buenos Aires, Argentina: Siglo XXI.

Feld, C. y Franco, M. (Dirs.) (2015). Democracia, hora cero: actores, politicas y debates en los inicios de la posdictadura. Buenos Aires, Argentina: Fondo de Cultura Económica.

Franco, M. (2012). Un enemigo para la nación: orden interno, violencia y "subversión". Buenos Aires, Argentina: Fondo de Cultura Económica.

García Reynoso, G. (1994). Memoria y olvido. El Rodaballo: Revista de política y cultura, 1, 20-21.

Grupo de Arte Callejero. (1997). Biografías. Buenos Aires, Argentina: Autor. Recuperado de http://cvaa.com.ar/03biografias/grupo_arte_callejero.php

Grupo Etcétera. (1998). About us. Recuperado de https://grupoetcetera.wordpress. com/about/

Historietas por la Identidad. (2012). Abuelas de Plaza de Mayo [Mensaje en un blog]. Recuperado de http://hisxi.blogspot.com.ar/

Hoveyda, F. (1967). Historia de la novela policiaca. Madrid, España: Alianza Editorial.

Jelin, E. (2006/2010). ¿Víctimas, familiares o ciudadano? Las luchas por la 
legitimidad de la palabra. En E. Crenzel (Coord.), Los desaparecidos en la Argentina: memorias, representaciones e ideas, 1983-2008 (pp. 227-249). Buenos Aires, Argentina: Biblos.

Laqueur, T. (1996). Bodies, details, and the humanitarian narrative. En L. Hunt (ed.), The new cultural history (pp. 176204). Berkeley, EE. UU.: University of California Press.

Longoni, A. (2009). Activismo artístico en la última década en Argentina: algunas acciones en torno a la segunda desaparición de Jorge Julio López. Errata: Revista de Artes visuales, 0, 12-35.

Lorenz, F. (2002). ¿De quién es el 24 de marzo? Las luchas por la memoria del golpe de 1976. En E. Jelin (Comp.), Las conmemoraciones: las disputas en las fechas "in-felices" (pp. 53-98). Buenos Aires, Argentina: Siglo XXI.

Lvovich, D. y Bisquert, J. (2008). La cambiante memoria de la dictadura: discursos públicos, movimientos sociales y legitimidad democrática. Buenos Aires, Argentina: Biblioteca Nacional.

Markarian, V. (2004). De la lógica revolucionaria a las razones humanitarias: los exiliados uruguayos y las redes transnacionales de derechos humanos. Cuadernos del CLAEH, 89, 85-108.

Nosiglia, J. E. (1985/2007). Botín de guerra. Buenos Aires, Argentina: Cooperativa Tierra Fértil.

Penchaszadeh, V. B. (2012). Uso de la identificación genética en la reparación de la violación del derecho a la identidad durante la dictadura militar argentina. En V. B. Penchaszadeh (Comp.), Genética y derechos humanos: encuentros y desencuentros (pp. 263-298). Buenos Aires, Argentina: Paidós.
Quintana, M. M. (2011). Sentido(s) de identidad: el caso de la apropiación/restitución de niños y jóvenes en Argentina. Teoria e Cultura 6(1). Recuperado de http://ojs2.ufjf.emnuvens.com.br/Teo riaeCultura/index

Rabotnikof, N. (2007). Memoria y política a treinta años del golpe. En E. Lida, H. Crespo y P. Yankelevich (Comps.), Argentina, 1976: estudios en torno al golpe de Estado (pp. 259-284). Buenos Aires, Argentina: Fondo de Cultura Económica de Argentina.

Semanaprofesional.com. 2005, septiembre 12. Homenaje a las Abuelas de Plaza de Mayo. Recuperado de http:/www.semanaprofesional.com: 80/?nota=1560

Sikkink, K. (1996). The emergence, evolution, and effectiveness of the Latin American human rights network. En E. Jelin y E. Hershberg (Eds.), Constructing democracy: Human rights, citizenship, and society in Latin America (pp. 59-84). Boulder, EE. UU.: Westview Press.

Symons, J. (1982). Historia del relato policial. Barcelona, España: Bruguera.

Taylor, D. (1997). Disappearing acts: Spectacles of gender and nationalism in Argentina's "Dirty War". Durham, RU: Duke University Press.

Taylor, D. (2002). "You are Here": The DNA of performance. The Drama Review, 46(1), 149-169.

Taylor, D. (2006). Trauma and performance: lessons from Latin America. PMLA, 121(5), 1674-1677.

Taylor, D. y Fuentes M. (Coords.) (2011). Estudios avanzados de performance. Ciudad de México, México: Fondo de Cultura Económica.

Ursi, M. E. y Verzero L. (2011). Teatro militante de la década de los setenta y acciones 
estético-politicas de los 2000: del teatro militante a los escraches. Ponencia presentada en IV Seminario Internacional Políticas de la Memoria: Ampliación del campo de los derechos humanos. Memoria y perspectivas, Buenos Aires, Argentina. Recuperado de http://conti. derhuman.jus.gov.ar/2011/10/mesa_26/ ursi_verzero_mesa_26.pdf

Valdéz, P. (2001). Tiempo óptimo para la memoria. En B. Groppo y P. Flier (Comps.), La imposibilidad del olvido: recorridos de la memoria en Argentina, Chile y Uruguay (pp. 63-82). La Plata, Argentina: Margen.

Vezzetti, H. (2002). Pasado y presente: guerra, dictadura y sociedad en la Argentina. Buenos Aires, Argentina: Siglo XXI.

Villalta, C. (2006). Cuando la apropiación fue adopción: sentidos, prácticas y reclamos en torno al robo de niños. Cuadernos de Antropología Social, 24, 147-173. Recuperado de http://www.scielo.org. ar/pdf/cas/n24/n24a08.pdf 